\title{
Patient and Physician Perspectives in a Case of Severe Traumatic Brain Injury
}

Rhoderick M. Casis

Received: August 4, 2018 / Published online: November 10, 2018

(C) The Author(s) 2018

\begin{abstract}
Traumatic brain injury is a challenge for general practitioners and specialists worldwide due to the heterogeneous clinical picture, secondary injuries and complex treatment including surgery, medication, intensive care, nutrition and rehabilitation. This case report is about a TBI patient with a score of four on the Glasgow Coma Scale when she was transferred from the primary hospital to our center. Her condition, treatment options and expectations were discussed with the relatives. The patient was subjected to surgery and received pharmacologic intervention including a neurotrophic drug and extensive rehabilitation measures including occupational therapy. Considering the patient's remarkable recovery, a combination of multiple treatment approaches seems promising in patients with severe traumatic brain injury.
\end{abstract}

Keywords: Cerebrolysin; Traumatic brain injury; Neuroregeneration; Neurorecovery

Enhanced digital features To view enhanced digital features for this article go to https://doi.org/10.6084/ m9.figshare.7258007.

R. M. Casis $(\square)$

St. Luke's Medical Center Quezon City, 279

Cathedral Heights, E. Rodriguez Sr. Ave, 1123

Quezon City, Metro Manila, Philippines

e-mail: bmcasis@hotmail.com

\section{INTRODUCTION}

Traumatic brain injury (TBI) is a global health problem and a common condition seen by every clinician. It is a major concern in all countries because it consumes healthcare resources and puts a tremendous strain on a government's healthcare budget. A large percentage of TBI patients suffered from vehicular accidents. In a meta-analysis of individual patient data in moderate and severe TBI, the IMPACT study group found a very similar distribution: the percentage of TBIs caused by road traffic incidents varied between 53\% and 80\%, and the percentage of TBIs caused by falls varied between $12 \%$ and $30 \%[1,2]$. Furthermore, a significant number of survivors was dependent on a caregiver in their activities of daily living. Similarly, in St. Luke's Medical Center in Quezon city, Philippines, almost $40 \%$ of the admission and referral patients suffered from traumatic brain injury. However, improving treatment should not only result in increased survival but also in improved functional outcome. Thus, new treatment concepts that improve the benefits for the patients should be explored.

The primary aim of this article is to provide help and information on additional treatment of traumatic brain injury, especially severe TBI. Improving the treatment of severe traumatic 
brain injury through better understanding of its pathophysiology and information about innovative treatment will help clinicians in treating TBI. Hopefully, new and well-designed studies will open avenues for new and innovative treatments to be accepted as beneficial to patients. Eventually, this will help in improving clinical guidelines on its treatment, which will potentially benefit patients with TBI.

\section{THE PATIENT'S CASE}

My patient, a 57-year-old female, was involved in a vehicular accident. She was hit by a speeding vehicle while crossing a busy street. Immediately after the accident, she was still able to say her name and talk to people around her. After $2 \mathrm{~h}$ she became drowsy. When she was brought to the primary hospital, she had a Glasgow Coma Scale (GCS) score of 13/15. According to the initial CT scan, she suffered from an acute right frontotemporoparietal subdural hematoma. She was still in the emergency room when she started to deteriorate, now with a GCS score of $7 / 15$. The right pupil was noted to be dilated and non-reactive to light. With a GCS score of $6 / 15$, she was intubated and was transferred to the emergency department of St. Luke's Medical Center. She received mannitol at a dose of $20 \mathrm{mg}$ every $4 \mathrm{~h}$ intravenously. Unfortunately, she deteriorated further to GCS $4 / 15$. She received another bolus of $40 \mathrm{mg}$ of mannitol upon consultation with the neurosurgeon. Her GCS score improved to $6 / 15$, and the decision for emergency surgery was made.

All procedures performed in this study involving the patient were in accordance with the ethical standards of the institutional and/or national research committee and with the 1964 Helsinki Declaration and its later amendments or comparable ethical standards. Informed consent was obtained from the patient or her representative for all the procedures done.

\section{PHYSICIAN'S ACCOUNT}

When I was informed about the patient in the emergency department and that her condition was deteriorating, I immediately asked them to give $40 \mathrm{mg}$ of mannitol as a bolus dose and to repeat the cranial CT scan. I told the doctor in the emergency room that I was on my way to the hospital. I entered a nearly full emergency room with every physician taking care of a patient. In the critical area, I saw the patient hooked to a ventilator. She still had traces of blood on some areas of her face. She had a periorbital hematoma on the right side, making examination of her right eye difficult. I noticed that her right pupil was dilated with no reaction to light. Her left pupil was $3 \mathrm{~mm}$ reactive to light. On further examination, she was responding to painful stimulation by withdrawing her left upper extremity with no eye opening. I asked for the CT scan images and saw that besides the right acute subdural hematoma, she also had multiple contusion hematomas of the right frontal, temporal and parietal lobes (Fig. 1a). There was a significant midline shift and signs of uncal herniation. All of these CT scan findings indicated a serious prognosis for the patient. I talked to her daughter and emphasized the need for immediate surgery, discussing the procedure to be done and and possible outcomes. The high possibility of death even with surgery and the probable neurologic deficits if the patient survived were also discussed. She gave her consent for the surgery. The patient was prepared for immediate surgery and brought to the emergency department operating suite. The planned surgery was craniotomy with evacuation of the acute subdural hematoma and intracerebral hematoma with possible decompressive hemicraniectomy.

A burr hole was made in the temporal area and enlarged to expose the tense dura. The dura was opened, and the acute subdural hematoma was suctioned. After a significant volume of blood had been evacuated, we proceeded with the frontotemporoparietal craniotomy. Upon lifting off the bone flap, the dura was noted to be tense with blood underneath. The exposed dura was opened, and a substantial volume of acute subdural hematoma was evacuated. Burst frontal and temporal lobes were noted, and a significant amount of intracerebral hematoma was evacuated. Bleeding areas of the brain were cauterized, and devitalized brain tissues were 
a

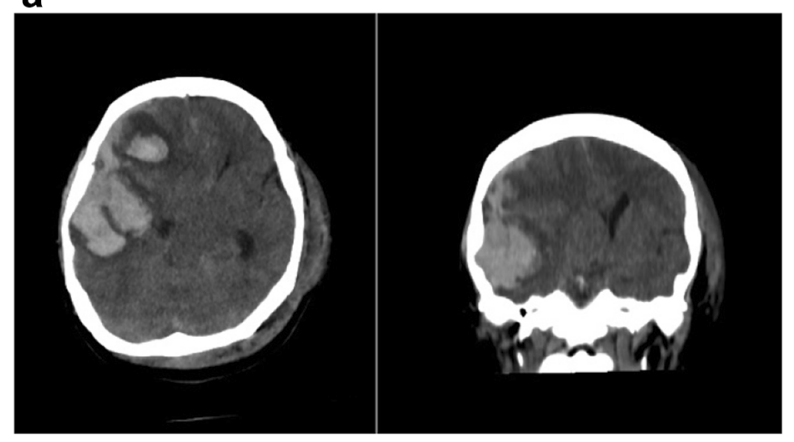

C

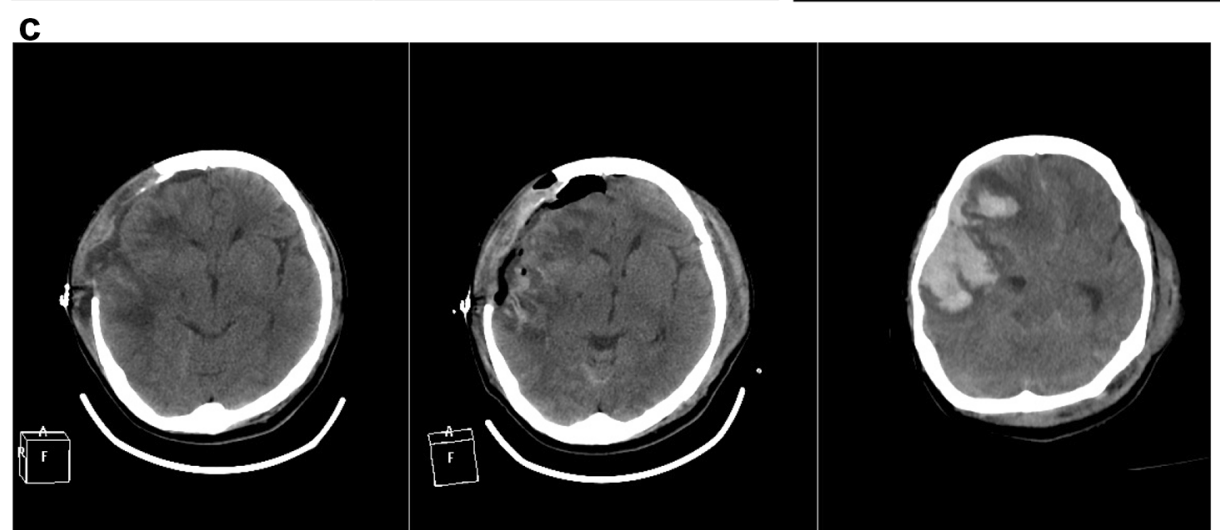

b

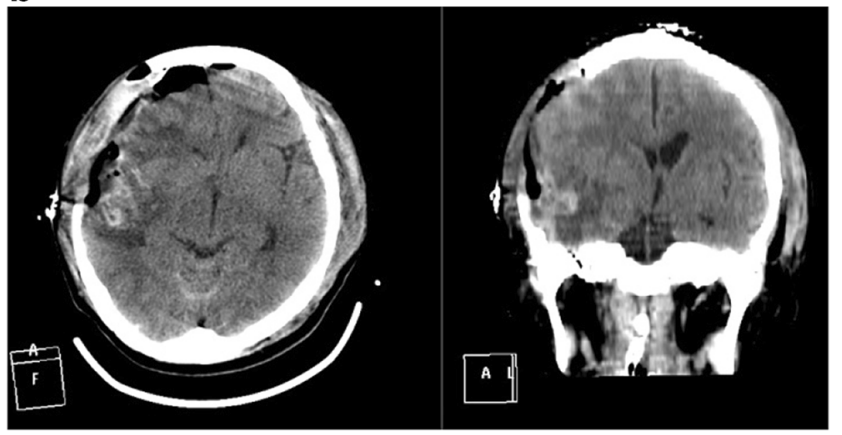

d

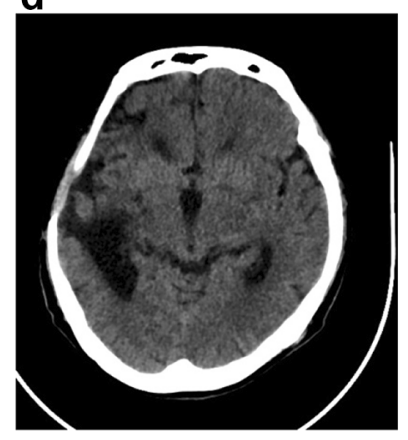

Fig. 1 Patient's cranial CT scans. a Cranial CT scan at the emergency department showing multiple hemorrhagic contusions, a subdural hematoma and midline shift. b Cranial CT scan $24 \mathrm{~h}$ after the first surgery with decreased mass effect and bone defect. c Cranial CT scan

also removed. The brain was noted to be pulsating but still significantly swollen. It was decided to do duraplasty and not to put back the bone for decompression of the swollen brain. Intracranial pressure monitoring was not done because it is not a standard procedure in our hospital for large decompressive craniectomies. The scalp was closed by layer with a

28 days after the first surgery compared with $24 \mathrm{~h}$ after the surgery and preoperatively. d Cranial CT scan 9 months after injury with cranioplasty showing minimal encephalomalacia

closed drain placed through a separate stab incision.

The patient was then brought to the neurocritical care unit, still maintained on a ventilator. She was given medical decompression using mannitol. The need for medical decompression was explained to the relatives including how it would be progressively decreased. An 
anticonvulsant was also given. The surgery including the findings were explained to the patient's children and also that her condition was still critical. A follow-up cranial CT scan showed near complete evacuation of the contusion hematomas and acute subdural hematoma with good expansion of the brain (Fig. 1b).

Less than $24 \mathrm{~h}$ after the surgery, the patient was still in critical condition. Knowing the limitations of surgery for the other problems of TBI, I decided to try other means to help the patient in her recovery. I informed her daughter about a medicine that is used for treatment of brain injuries caused primarily by stroke but is also used in TBI. I explained that Cerebrolysin ${ }^{\circledR}$ consists of purified peptides from porcine brain and is given intravenously. I gave examples of my patients who had good recovery after brain injury but mentioned that these were mostly from strokes. The daughter agreed to the added treatment. The medicine was to be given at a dose of $50 \mathrm{ml}$ once a day for 14 days. No other neuroprotective or neuroregenerative drug was given to the patient.

The patient improved and was eventually weaned off the ventilator. She progressively improved, and a repeat cranial CT scan was done 28 days after her first surgery (Fig. 1c). She underwent cranioplasty where the bone that was removed to accommodate the brain swelling was put back. This was done 41 days after the first surgery. The patient was discharged 5 days after the repair of the decompressive craniotomy. On the patient's last follow-up 9 months post-TBI, she had a Glasgow Outcome Scale score of 5, indicating good recovery. She was examined and showed good cognitive function including understanding and judgment. Her visual examination was normal including gross confrontation tests. She mentioned that she had started to work but was taking things slowly with her work load. A repeat cranial CT scan was also done during this time (Fig. 1d).

The treatment options used for this patient were in accordance with the institutional guidelines on the care of patients with severe traumatic brain injury. Furthermore, no study was conducted on humans or animals in this article.

The following interview with the patient and her daughter reflects their impressions regarding the treatment and their feelings throughout the whole recovery process.

\section{DAUGHTER'S ACCOUNT}

\section{Please Describe the Therapies}

The neurosurgeon recommended that my mom be given an intravenous injection of brain neuropeptides that has been shown to stimulate brain regeneration in studies, particularly for patients with stroke, albeit a bit expensive. Although my mother suffered a traumatic brain injury and not a stroke, the indications for the drug were very similar, and so I consented.

\section{Was This the First Therapy that was Administered?}

It was one of the first medications to be given after the craniotomy and evacuation of hematoma.

\section{Were There Positive Outcomes on Your Mother's Health as a Result of This Therapy?}

The drug was one of many lifesaving procedures and drugs given to my mother during the critical period, but the speed and level of her recovery from the accident was honestly beyond what I was expecting. Within a week, she was awake, and within a month, she was mobile and conversant. Within a few months, she had almost fully recovered, aside from some residual vision and hearing impairments.

\section{Were There Negative Side Effects and If So Can You Describe These?}

None that I know of. The drug was given together with other drugs and procedures. 


\section{PATIENT'S ACCOUNT}

\section{How Did the Injury Impact Your Life?}

I cannot remember anything much from the first few days or weeks after the accident as I was unconscious while in the ICU.

As I became awake, the more I became aware of the transition from staying healthy to being unwell. Slowing down was new to me; I had to depend on nurses at the hospital for lying down and doing my personal hygiene. The headache I felt made me aware of the brain connection to foot sole pressure points, muscle tiredness, IV needle punctures, hunger, pain relief from warmth, a compression sensation of cold water drops, and hot porridge in my mouth and the taste of yoghurt. Swallowing posed a discomfort. Drinking water always lodged partly in some airway; to cough it up required correct positioning of the neck. The tongue felt rigid when swallowing vitamins, pills.

\section{Since Your Diagnosis, How Would You Describe Your Experience of Your Indication? In What Way Does It Impact on Your Quality of Life?}

When I was discharged and faced the new situation, I said to myself, "Is this my new present?" My mind raced to delegate work but I had to contend with taking orders, even from my children, and being sidelined at home.

Lethargy and a bit of time warp due to irregular sleep. The lying position was an ordeal, especially the magnified pain in the head. I experienced vertigo when sitting up.

Balance meant holding and leaning to grasp. I also learned to relax, pause until I could stand on steady feet. To wake up regularly at 6 a.m. without feeling sleepy still. I had to practice in preparation for returning to work, had to be more alert when I woke up and to focus my vision.

Hearing loss in the left ear made me participate less in group conversations at social gatherings. Peripheral dark vision and easily tired eyes meant I had to maximize use of rested eyes working in good light.
I learned acceptance, to deal with my limitations. I understood what I could still do despite hearing loss in the left ear and distance and peripheral vision impairment. My children helped me to find my lost self again: we played scrabble; I got new glasses and fixed my teeth; they accompanied me to physical therapy, which I completed as out-patient.

I had part of my old self again, I felt completely surrounded by love. I did not feel less capable. I caught up with work, I cook, go to the grocery, read, sew and attend Mass. I was content and grateful.

\section{Has It Affected Your Physical or Mental Health?}

Definitely, the physical appearance was the first I noticed. I had to eat, continue physical therapy to regain a correct gait and facial expression. My mind was sharp; I had a few short-term memory lapses but my speech was smooth and coherent.

\section{How Has It Impacted Your Work Life?}

Very kind bosses made it easy to find solutions. The work schedule began with a 2-day week. I had to prepare for sitting upright the whole morning and try to see clearly without overworking.

I increased my working time from 2 to $3 \mathrm{~h}$ in June 2017 to $4-6 \mathrm{~h}$ in January 2018. Now I can extend as long as needed, especially for business meetings.

\section{How Has It Impacted Your Family and Social Life?}

No problem, I attend social events even more frequently than before.

\section{How Has It Impacted Your Leisure Activities?}

I still go to the grocery; I read less though. I cannot go out alone, so I rediscovered board games, painting, sewing, and I have time for TV and home movies. Praying became my outlet. 


\section{How Regularly Have You Consulted a Physician Since Your Diagnosis?}

I completed my therapy and follow-up sessions for physical therapy. I saw the neurologist as appointed. Further consultations were not required since I had no complications.

\section{DISCUSSION}

TBI is a complex disorder and difficult to treat. The subtypes and heterogeneity of TBI make a generalized treatment approach inadequate as it does not address all the problems and changes in a patient with TBI. Secondary brain injury is a complex pathophysiologic process that often causes permanent injury, and clinicians and neuroscientists are facing the question of how to address or stop its progression. Most residual deficits from severe TBI are attributed to secondary brain injury.

Mannitol, which decreases intracranial pressure, is a double-edged sword as with prolonged use it may cause brain swelling [3]. Thus, mannitol is usually discontinued after 1 or 2 weeks, depending on the condition of the patient.

Intracranial pressure monitoring after primary decompressive hemicraniectomy is not standard of care in our hospital; it rather depends on the individual's condition. However, it is still a controversial topic in TBI, and its need is investigated in the study by Picetti et al. [4].

Another concern with respect to severe TBI is the prognosis of the patient. Several studies reported independency in 30-65\% of patients, but functional recovery was very slow with some extending up to even 12 months [5]. Others studies reported a fast improvement within the first 6 months [6] and slower improvement lasting up to 1 or 2 years post-TBI. Some studies even mention improvement after 2 years although the amount of improvement is minimal during this period $[7,8]$. The IMPACT trial looked for factors predicting the outcome of patients with severe TBI, such as the GCS score and pupillary activity. A low score and anisocoria can mean a poor patient outcome [9], as was the case in our patient when she arrived in the emergency department. Other variables include age, associated injuries, hypoxia, hypotension, CT scan findings, glucose and hemoglobin levels. Some patients with severe TBI improve significantly after surgical treatment, but these are patients with epidural or subdural hematomas and very small or no cerebral contusions. Our patient had significant hemorrhagic contusions of the right frontal, temporal and parietal lobes. Studies in severe TBI reported a mortality rate of approximately $30 \%[10,11]$. Of patients discharged, $5-15 \%$ were in a chronic vegetative state, and half regained consciousness within a year after injury but were still severely disabled [12].

Surgical treatment to reduce the mass effect of the intracranial hematoma also depends on hematoma volume, location and patient's neurologic status. Decompressive hemicraniectomy carries problems with edema. However, despite maximal medical support and decompression, there is still a need for further treatment options that address the necessity to attenuate the deleterious effects of secondary brain injury. Newer drugs such as Cerebrolysin-when given early enough in the emergency room or in the intensive care unit-may contribute to an improved outcome in TBI patients. Despite the use of neuroprotective agents over the last several years, no definite agreement has been reached about how effective these medications are. Recently, a few studies have stated that some of these neuroprotective agents have no effect on the survival and recovery of TBI patients. This is especially true for steroids and glucocorticoids in TBI patients [13-15]. "The use of steroids is not recommended for improving outcome or reducing ICP. In patients with severe TBI, high-dose methylprednisolone was associated with increased mortality and is contraindicated" [16]. Amantadine was reported to accelerate recovery [17], and several studies with citicoline reported positive trends as cited by Secades et al. [18]. However, the conclusion of the COBRIT trial was: "Among patients with traumatic brain injury, the use of citicoline compared with placebo for 90 days did not result in improvement in functional and cognitive status" [19], and a meta-analysis concluded that "the results obtained from the EBM 
should be used as a guide or orientation on how to act in everyday practice, and, together with personal experience, try to improve the outcome obtained" [18]. If these neuroprotective agents are not as effective in treating patients with TBI-especially severe TBI-we should rethink our goals for its treatment.

We have guidelines regarding the treatment of the primary injury including intracranial hematomas and increased intracranial pressure, and the progress we have made in the treatment of severe TBI is reflected in the new guideline for the treatment of severe traumatic brain injury [20]. However, regarding neuroprotective and neuroregenerative treatment, there is still no guideline available; thus, individual experiences still play a significant role in the use of these treatments. Research on neuroprotection has been done over the last 30 years, but conclusive evidence is still not available. The area of neuroregeneration, neuroplasticity and neurorecovery is still relatively new in neurosciences, and the exact mechanisms are still under investigation. Newer drugs such as Cerebrolysin are changing clinicians' perceptions. Cerebrolysin is a peptide preparation that mimics the action of endogenous neurotrophic factors and was shown to be safe and effective in clinical studies [21, 22]. Other neuroprotective agents showed some effects on TBI but to a lesser extent [23]. Enhanced neurorecovery after Cerebrolysin treatment has also been shown recently in ischemic stroke [24].

\section{CONCLUSION}

There is no magic bullet in the treatment of severe TBI. Our treatment has to be individualized based on EBM, personal experience and our environment. However, we have to remember that the future is bright with better research and understanding of TBI. Newer information, from well-conducted randomized clinical trials, will definitely help in the treatment of TBI patients, especially those with severe TBI. In the future, the combined treatment and the multispecialty approach in the treatment of TBI will greatly benefit our patient.

\section{ACKNOWLEDGEMENTS}

I thank the patient and her daughter for allowing me to report the case and for writing and sharing their experience and thoughts about the patient's illness.

Funding. No funding or sponsorship was received for this study or publication of this article.

Authorship. All named authors meet the International Committee of Medical Journal Editors (ICMJE) criteria for authorship for this article, take responsibility for the integrity of the work as a whole and have given his approval for this version to be published.

Disclosure. Rhoderick M. Casis was a principal investigator for a site in the Philippines for The CAPTAIN Trial: Cerebrolysin Asian Pacific Trial in Acute Brain Injury and Neurorecovery (CAPTAIN).

Compliance with Ethics Guidelines. All procedures performed in studies involving human participants were in accordance with the ethical standards of the institutional and/or national research committee and with the 1964 Helsinki Declaration and its later amendments or comparable ethical standards. Informed consent was obtained from the patient or her representative included in the study. Informed consent was taken from the patient and her daughter to write about her case and their thoughts on the patient's illness.

Data Availability. Data sharing is not applicable to this article as no data sets were generated or analyzed during the current study.

Open Access. This article is distributed under the terms of the Creative Commons Attribution-NonCommercial 4.0 International License (http://creativecommons.org/licenses/ by-nc/4.0/), which permits any noncommercial use, distribution, and reproduction in any medium, provided you give appropriate credit to the original author(s) and the source, 
provide a link to the Creative Commons license, and indicate if changes were made.

\section{REFERENCES}

1. Theadom A, Feigin V, Reith F, Maas A. Epidemiology of traumatic brain injury. In: Winn HR, editor. Youmans and Winn neurological surgery. Philadelphia: Elsevier; 2017.

2. Finkelstein E, Corso P, Miller T. The incidence and economic burden of injuries in the United States. New York: Oxford University Press; 2006.

3. Wakai A, McCabe A, Roberts I, Schierhout G. Mannitol for acute traumatic brain injury. Cochrane Database Syst Rev. 2013;8:CD001049.

4. Servadei F, Picetti E. Intracranial pressure monitoring and outcome in traumatic brain injury: the probe does matter? World Neurosurg. 2015;83:732-3.

5. Christensen B, Colella B, Inness E, Hebert D, Monette G, Bayley M, Green RE. Recovery of cognitive function after traumatic brain injury: a multilevel modeling analysis of Canadian outcomes. Arch Phys Med Rehabil. 2008;89(12 Suppl 2):S3-15.

6. Anderson J, Schmitter-Edgecombe M. Recovery of time estimation following moderate to severe traumatic brain injury. Neuropsychology. 2011;25(1):36-44.

7. Powell J, Heslin J, Greenwood R. Community based rehabilitation after severe traumatic brain injury: a randomised controlled trial. J Neurol Neurosurg Psychiatry. 2002;72:193-202.

8. Shakur H, Roberts I, Bautista R, CRASH-2 trial collaborators, et al. Effects of tranexamic acid on death, vascular occlusive events, and blood transfusion in trauma patients with significant hemorrhage (CRASH-2): a randomised, placebo-controlled trial. Lancet. 2010;376:23-32.

9. Olivecrona M, Koskinen LO. The IMPACT prognosis calculator used in patients with severe traumatic brain injury treated with an ICP-targeted therapy. Acta Neurochir (Wien). 2012;154:1567.

10. Grigorakos L, Alexopoulou A, Tzortzopoulou K, Stratouli S, Chroni D. A predictors of outcome in patients with severe traumatic brain injury. J Neurosci Clin Res. 2016;1:1.

11. Martins ET, Linhares MN, Sousa DS, Schroeder HK, Meinerz J, et al. Mortality in severe traumatic brain injury: a multivariated analysis of 748 Brazilian patients from Florianópolis city. J Trauma. 2009;67(1):85-90.

12. McMillan TM, Teasdale GM, Weir CJ, Stewart E. Death after head injury: the 13-year outcome of a case control study. J Neurol Neurosurg Psychiatry. 2011;82:931.

13. Maas AI, Stocchetti N, Bullock R. Moderate and severe traumatic brain injury in adults. Lancet Neurol. 2008;7:728.

14. Skolnick BE, Maas AI, Narayan RK, et al. A clinical trial of progesterone for severe traumatic brain injury. N Engl J Med. 2014;371:2457.

15. Wright DW, Yeatts SD, Silbergeit R, et al. Very early adminstration of progesterone for acute traumatic brain injury. N Engl J Med. 2014;371:2457.

16. Brain Trauma Foundation TBI Guidelines 2016. Guidelines for the management of severe traumatic brain injury, 4th ed. Neurosurgery 2016;3:p76.

17. Giacino JT, Whyte J, et al. Placebo-controlled trial of amantadine for severe traumatic brain injury. N Engl J Med. 2012;366:819-26.

18. Secades Julio. Citicoline for the treatment of head injury: a systematic review and meta-analysis of controlled clinical trials. J Trauma Treat. 2014;4:227.

19. Zafronte RD, Bagiella E, Ansel BM, et al. Effect of citicoline on functional and cognitive status among patients with traumatic brain injury: Citicoline Brain Injury Treatment Trial (COBRIT). JAMA. 2012;308:1993-2000.

20. Brain Trauma Foundation TBI Guidelines 2016. Guidelines for the management of severe traumatic brain injury, 4th ed. Neurosurgery 2016;0:3

21. He J, Fan J, Geng S. Efficacy of cerebrolysin in acute brain trauma. Chin J Clin Pract Med. 2002;4:71-2.

22. König P, Wannders R, Witzmann A, et al. Cerebrolysin in traumatic brain injury-a pilot study of a neurotrophic and neurogenic agent in the treatment of acute traumatic brain injury. J Neurol Neurochir Psychiatr. 2006;7:12-20.

23. El Sayed I, Zaki A, Fayed AM, Shehata GM, Abdelmonem S. A meta-analysis of the effect of different neuroprotective drugs in management of patients with traumatic brain injury. Neurosurg Rev. 2018;41:427-38.

24. Muresanu DF, Heiss WD, Hoemberg V, et al. Cerebrolysin and recovery after stroke (CARS): a randomized, placebo-controlled, double-blind, multicenter trial. Stroke. 2016;47:151-9. 